\title{
Epidemiological, Clinical and Therapeutic Profile of Obstructive Renal Failure
}

\section{Kimassoum Rimtebaye ${ }^{1 *}$, Cyril Kamadjou², Divine Eyongeta ${ }^{3}$, Annie Kameni², Justin Kamga $^{4}$, Bertin Njinou ${ }^{1}$}

\author{
${ }^{1}$ National General Referal Hospital, N'Djamena, Chad \\ ${ }^{2}$ Medico-surgical Center of Urology and Mini Invasive Surgery, Douala, Cameroon \\ ${ }^{3}$ Regional Hospital, Limbe, Cameroon \\ ${ }^{4}$ General Hospital, Yaounde, Cameroon \\ Email: *melinarim@yahoo.fr
}

How to cite this paper: Rimtebaye, K., Kamadjou, C., Eyongeta, D., Kameni, A., Kamga, J. and Njinou, B. (2018) Epidemiological, Clinical and Therapeutic Profile of Obstructive Renal Failure. Open Journal of Urology, 8, 89-92.

https://doi.org/10.4236/oju.2018.84010

Received: March 12, 2018

Accepted: April 15, 2018

Published: April 18, 2018

Copyright (C) 2018 by authors and Scientific Research Publishing Inc. This work is licensed under the Creative Commons Attribution International License (CC BY 4.0).

http://creativecommons.org/licenses/by/4.0/

\begin{abstract}
Aim: To describe the epidemiological, clinical, etiologic and therapeutic aspects of patients with acute obstructive renal failure at the Medical Surgical Center of Urology (MSCU). Materials and methods: this was a descriptive retrospective study of 106 patient records treated for acute renal failure from January 2012 to December 2016. Patients came for spontaneous consultation or were referred. They had benefited from a clinical and paraclinical assessment at the end of which the diagnosis of acute renal failure was retained and then an effective management at the MSCU. The variables studies were clinical, paraclinical, therapeutic and progressive. The treatment included: hemodialysis, urinary diversion (suprapubic, urethrovesical and ureteral), trans-urethral resection of the prostate, trans-urethral resection of the bladder, nephrostomy, endoscopic incision of catheter valves, posterior urethra or laparoscopic nephroureterectomy as indicated. The emergency treatments consisted of removing the obstacle and the etiological treatment was done later. External follow-up consultation varied by etiology. Results: In 4 years we had treated 106 patients, a frequency of $26.5 \%$. The average age was 47.83 years with extreme of 2 and 80 years old. The sex ratio was 68 men for 38 women. The mean serum creatinine level was $37.8 \mathrm{mg} / \mathrm{l}(335 \mu \mathrm{mol} / \mathrm{l})$. The etiologies were: prostatic pathologies $(n=38)$, lithiasic pathologies $(n=20)$ and gynecological pathologies $(\mathrm{n}=18)$. The treatments were: endoscopic resection of prostate ( $\mathrm{n}$ $=24)$, bladder $(n=6)$, posterior urethral valves $(n=4)$, JJ probe $(n=27)$ and nephrostomy $(\mathrm{n}=23)$. The result was good (normalization of creatinine serum) in 79 patients, the persistence of elevated serum creatinine was observed in 4 patients and 18 patients died. Conclusion: Acute obstructive renal failure is a common diagnosis in our exercise setting at MSCU where it can be managed with respect to our technical platform.
\end{abstract}




\section{Keywords}

Renal Failure, Nephrostomy, Creatinine, Endoscopic Resection

\section{Introduction}

Obstructive acute renal failure is defined as the deterioration of renal function related to a disorder of urines evacuation. It is a common pathology in urology of multiple and varied etiologies [1]. Its frequency is diversely appreciated according to the studies [2]. This pathology is little studied in Africa as evidenced by the rarity of publications dealing with obstructive acute renal pathologies [3]. The etiological diagnosis uses notably imaging scan, tomo-densitometry or even retrograde urethrocystography. Obstacle removal is the action to be taken urgently [1] before proceeding to the often-definitive treatment that will take into account the etiology. The prognosis is generally good when the treatment is early.

The purpose of this work is to describe the clinical, paraclinical aspects of acute obstructive renal failure and to report our MSCU support.

\section{Materials and Methods}

This was a descriptive retrospective study of 106 patients treated for acute renal deficiency from January 2012 to December 2016 at the Medical Surgical Center of Urology (MSCU) in Cameroon at Douala. Patients came for spontaneously consultation or were referred by a colleague. They had benefited, from a clinical and paraclinical assessment at the end of which the diagnosis of obstructive renal insufficiency was retained, of a support and a follow-up at the MSCU. The variables studies were clinical, paraclinical, therapeutic and evolutionary. Clinical variables concerned: general condition, age, sex, lower back pain, fever, macroscopic hematuria, bladder globe and rectal touchfor men. The paraclinical variables were: serum creatinine, blood ionogram, urinary tract ultrasound, and abdominal computed tomography. Therapeutic variables were: hemodialysis, urinary derivation (supra-pubic and urethral catheterizations), endoscopic urethrotomy, endoscopic incision, trans-urethral resection of the prostate (TURP), trans-urethral resection of the bladder (TURB), nephrostomy, placement of JJ probes, and laparoscopic nephroureterectomy. The evolutionary variables interest at: improvement of renal function (normalization of creatinine serum level), hydronephrosis, persistence of elevated creatinine and death.

The study had the authorization of the Ethics Committee, the administrative authorization of the MSCU. Patient informed consent was sought and obtained for the anonymous use of photographs for scientific purposes.

\section{Results}

In 4 years of activity at MSCU, we treated 106 patients with obstructive renal 
failure, a frequency of $26.5 \%$. The average age of patients was 47.83 years old with extremities of 2 and 80 years and a sex ratio of 68 men for 38 women. The mean serum creatinine level was $37.8 \mathrm{mg} / \mathrm{l}(335 \mu \mathrm{mol} / \mathrm{l})$ with extreme of $15 \mathrm{mg} / \mathrm{l}$ $(133 \mu \mathrm{mol} / \mathrm{l})$ and $230 \mathrm{mg} / \mathrm{l}(2036 \mu \mathrm{mol} / \mathrm{l})$.

The reason for consultation was for: renal colic $(n=48)$, urinary tract necrosis $(n=29)$, bladder urine complete retention $(n=17)$, gross hematuria $(n=9)$, and urinary tract infections with repetition $(n=3)$. The etiologies were: obstructive lithiasis $(n=23)$, benign prostatic hypertrophy $(n=19)$, cancer of the prostate $(\mathrm{n}=19)$, cervical cancer $(\mathrm{n}=18)$, tumors of the uterus bladder $(\mathrm{n}=8)$, Accidental ligation of the ureter during hysterectomies $(n=7)$, posterior urethral valvus $(\mathrm{n}=6)$, ureteral stenosis $(\mathrm{n}=5)$, and excretory tract tumors superior $(\mathrm{n}=1)$.

Urgent treatment consisted of: a double J catheter $(\mathrm{n}=27)$, a nephrostomy ( $\mathrm{n}$ $=24)$, a urine derivation $(n=11)$, hemodialysis $(n=6)$. The etiologic treatment consisted in: a TURP $(n=15)$, a cervico-prostatic endoscopic tumor $(n=9)$, a TURB $(n=6)$, an endoscopic incision of the posterior urethral valves $(n=4)$, an endoscopic internal urethrotomy $(n=3)$ and a laparoscopic nephroureterectomy $(\mathrm{n}=1)$.

These treatments resulted in an improvement in renal function $(n=85)$, persistence of renal failure $(n=3)$, stabilization of hydronephrosis $(n=6)$, and disappearance of hydronephrosis $(\mathrm{n}=100)$ and 18 deaths. Deaths were observed in patients who had: cervical cancer $(n=5)$, prostate cancer $(n=6)$, posterior urethral valves $(n=5)$, and bladder tumor $(n=2)$.

\section{Discussion}

Acute obstructive renal deficiency is a common pathology encountered in urological practice generally related to cervico-prostatic obstruction. All ages are incriminated, but it is much more common in age groups above 50 years, particularly in relation to prostatic pathology [3].

In women, obstructive renal failure is sometimes related to gynecological tumors responsible for extrinsic compression of the ureters. Whatever the etiology of acute renal insufficiency, the removal of obstacles remains the main saving gesture to be carried out urgently as recommended by Herody [1]. Some etiologies are easily curable including benign prostatic hypertrophy, urolithiasis, stenosis of the urethra, uterine fibroid or accidental ligation of the ureters and explains the high number of good results obtained in the study. Others have a prognosis often pejorative notably: prostate cancer, cancers of the gynecological sphere, valves of the posterior urethra or tumors of the excretory pathways justifying the number of deaths related to these etiologies in our study. In our context, tumors of the excretory tract are complications of bilharzeal infestation and occur in young people between 30 and 40 years old [4].

The advent of endoscopy in urology made it possible to perform minimally invasive treatments with low morbidity and mortality which are: endoscopic resection of prostatic and bladder tumors, double J probe, incision posterior urethra and the internal urethrotomy for ureter stenosis. Patients whose general 
state is strongly altered as well as the renal function, are referred for some hemodialysis sessions before a purely urological support as reported by Gaudry et al. [5].

Despite the endoscopic incision of the valves of the posterior urethra, the disease tends to evolve for its own account explaining the recurrence of urinary infections or even the urinary sepsis cause of death.

The ligation or accidental section of the ureters must be recognized intraoperatively to avoid the installation of an obstruction of the upper excretory tract responsible for acute renal failure.

Regardless of the technique used to remove the obstruction, consideration should be given to monitoring the patient's diuresis and ionogram to prevent obstructive syndrome [1] [7].

\section{Conclusions}

Acute obstructive renal failure is a common pathology in urological practice in MSCU. The cervico-vesico-prostatic obstacle and the gynecological tumors dominate the etiology. The minimally invasive techniques of derivation in endoscopy improve the immediate support.

Hemodialysis in emergency situations precedes etiologic treatment for severe acute renal failure in a patient with a pronounced deterioration of the general condition.

\section{References}

[1] Herody, M. (2008) Management of Postobstructive Dieresis after Urological Treatment of Obstructive Anuria. Progrès en Urologie-FMC, 18, F25-F28.

[2] Haymann, J.P., Vinsonneau, C., Girshovich, A. and Daudon, M. (2017) Acute Obstructive Nephropathy: A Pathophysiological View. Néphrologie \& Thérapeutique, 13, S1-S5. https://doi.org/10.1016/j.nephro.2017.01.008

[3] Moussa Tondi, Z.M. , Moussa Diongole, H., Abdou, I., El, M.T. and Aboubacar, I. (2015) Profil épidémiologique, clinique et thérapeutique de l'insuffisance rénale aiguë obstructive au Niger. Néphrologie \& Thérapeutique, 11, 351. https://doi.org/10.1016/j.nephro.2015.07.281

[4] Odzébé, A.W.S., Bouya, P.A., NkouaMbon, J.B. and Ekat, M.H. (2011) Les tumeurs de vessie: Aspects épidémiologiques à Brazzaville. Journal Africain du Cancer, 3, 36-39.

[5] Gaudry, S., Charbi, K., Bénichou, N., Verney, C., Hajage, D. and Dreyfuss, D. (2017) Renal Replacement Therapy for acute Kidney Injury in the Intensive Care Unit. Néphrologie \& Thérapeutique, 13, S13-S21. https://doi.org/10.1016/j.nephro.2017.01.007

[6] Abbo, O., Bouali, O., Ballouhey, Q., Mouttalib, S., Lemandat, A., Decramer, S., Moscovic, J. and Galinier, P. (2013) Impact de l'âge au diagnostic sur le devenir à long terme des patients opérés de valves de l'urètre postérieur. Progrès en Urologie, 23, 144-149. https://doi.org/10.1016/j.purol.2012.10.015

[7] Guerrot, D. and Tamion, F. (2013) Obstructive Acute Renalfailure: The Intensivist's Viewpoint. Journal Européen des Urgences et de Réanimation, 25, 13-17. 